\title{
Simulation and Experimental Study of Corrugated Sheet Metal Stamping
}

\author{
B. ZHONG, H. MAO, C.J. LUO, W.Z. YU \& K. HE
}

Shenzhen Institutes of Advanced Technology, Chinese Academy of Sciences, Shenzhen, China

Shenzhen Key Laboratory of Precision Engineering

R.X. DU

The Chinese University of Hong Kong, Hong Kong

ABSTRACT: This paper concerned the stamping process of corrugated sheet metal for sealing device honeycomb manufacturing. GH536 foil with a thickness of $0.05 \mathrm{~mm}$ was used to produce corrugated sheet metal with semi-hexagonal profile. Finite element models for the corrugated sheet metal stamping process were built to analyze the forces and material deformation. The prototype molds with a pair of pressure dies were designed and tested. Then according to the curling phenomenon occurred in the experimental result of prototype molds, the optimized final molds was designed with three pairs of pressure dies. The formed corrugated sheet metal by the final molds was much better.

KEYWORD: Corrugated metal sheet; Stamping; Honeycomb manufacturing; Numerical simulation

\section{INTRODUCTION}

The metal honeycomb as shown in Figure 1 is a new type of porous material. It has been widely applied in rail transportation, aerospace, architecture and other occasions[1]. For relatively low density, low stiffness, controllable deformation and many other advantages, the honeycomb structure is ideal energy absorption material. In recent years, the honeycomb core is applied in steam turbines and turbine engine's sealing device to prevent steam leakage, ensure the safety of workers, and improve equipment efficiency [2].

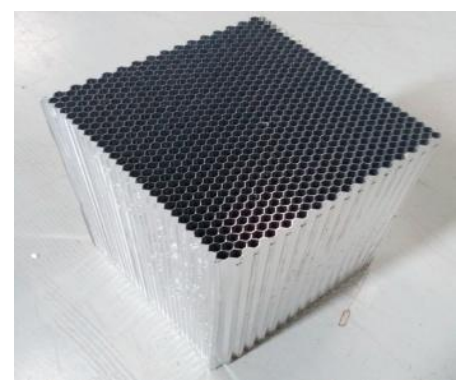

Figure 1. Metal honeycomb

The metal honeycomb used in sealing device is different from traditional metal honeycomb in material and manufacturing. Traditional honeycomb which is used as energy absorber and architecture material is commonly produced by bonding corrugated sheet metal together [3]. As nearly no adhesives can meet the working temperature of sealing device at $800{ }^{\circ} \mathrm{C}$, the commonly used honeycomb material in sealing device is Hastelloy- $\mathrm{X}$ which is formed into semi-hexagonal profile, and then welded together to give honeycomb structure.

This paper used GH536 foil with a thickness of $0.05 \mathrm{~mm}$. Its main component is $\mathrm{Ni}-\mathrm{Cr}-\mathrm{Fe}$, the chemical elements are listed in Table 1 and mechanical properties are shown in Table 2 [4]. The GH536 foil was stamped into corrugated sheet with semi-hexagonal profile for following welding process into honeycomb structure.

Table 1 Hastelloy GH536's chemical elements

\begin{tabular}{|c|c|c|c|c|}
\hline Elements & $\mathrm{C}$ & $\mathrm{Cr}$ & $\mathrm{Ni}$ & $\mathrm{Co}$ \\
\hline Percentage & $0.05 \sim 0.15$ & $20.5 \sim 23$ & $>50$ & $0.5 \sim 2.5$ \\
\hline Elements & $\mathrm{W}$ & $\mathrm{Mo}$ & $\mathrm{Fe}$ & $\mathrm{Al}$ \\
\hline Percentage & $0.2 \sim 1.0$ & $8 \sim 10$ & $17 \sim 20$ & 0.5 \\
\hline Elements & $\mathrm{Ti}$ & $\mathrm{Mn}$ & $\mathrm{N}$ & $\mathrm{S}$ \\
\hline Percentage & 0.15 & 1 & 1 & 0.015 \\
\hline Elements & $\mathrm{P}$ & $\mathrm{B}$ & $\mathrm{Cu}$ & \\
\hline Percentage & 0.025 & 0.01 & 0.01 & \\
\hline
\end{tabular}

Table 2 Hastelloy GH536's mechanical properties

\begin{tabular}{|c|c|}
\hline Solution temperature $\left({ }^{\circ} \mathrm{C}\right)$ & 1177 \\
\hline Density $\left(\mathrm{g} / \mathrm{cm}^{3}\right)$ & 8.28 \\
\hline Yield strength $(\mathrm{MPa})$ & 310 \\
\hline Tensile strength $(\mathrm{MPa})$ & 725 \\
\hline Elastic modulus $(\mathrm{GPa})$ & 206 \\
\hline Poisson's ratio & 0.3 \\
\hline Elongation $(\%)$ & 30 \\
\hline
\end{tabular}


The demanded specifications of the corrugated sheet metal is shown in Figure 2, the angles between adjacent sides $\theta 1=\theta 2=120^{\circ}$, side length $l_{1}=l_{2}=l_{3}=$ $0.8 \mathrm{~mm}$, thickness $\mathrm{t}=0.05 \mathrm{~mm}$.

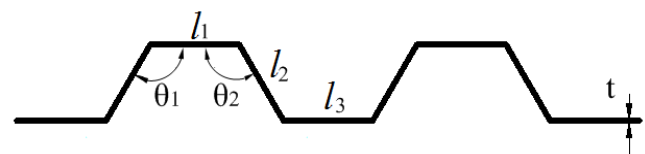

Figure 2. The demanded specifications of the corrugated sheet metal

\section{NUMERICAL SIMULATION}

The principle of stamping is that the part with desired shape and size is obtained by a method of permanent plastic deformation of work piece. This process is achieved by the normal contact force and tangential frictional forces between the mold and the work piece. The stamping process involves three nonlinear problems in mechanics.

(1)Geometric nonlinearity (Large displacement, rotation and deformation in the stamping process).

(2)Physical nonlinearity (Also known as material nonlinearity which refers to elastic-plastic deformation of the material).

(3)Boundary nonlinearity (Refer to non-linear relationship caused by contact friction between the die and work piece).

The development of computer technology and finite element method provides a new way for complex engineering calculation. This paper used explicit dynamic software ANSYS LSS-DYNA to simulate the corrugated sheet metal stamping process

\subsection{Original Design of Stamping Molds}

For the corrugated sheet metal stamping, special molds was designed as illustrated in Figure 3 and Figure 4. All the fillets are $0.1 \mathrm{~mm}$. The material of the molds is P20 \# steel. Since the GH536 foil is very thin, the deformation of molds is negligible in the forming process, so the molds can be regarded as rigid in simulation. The material properties of the molds are listed in Table 3.

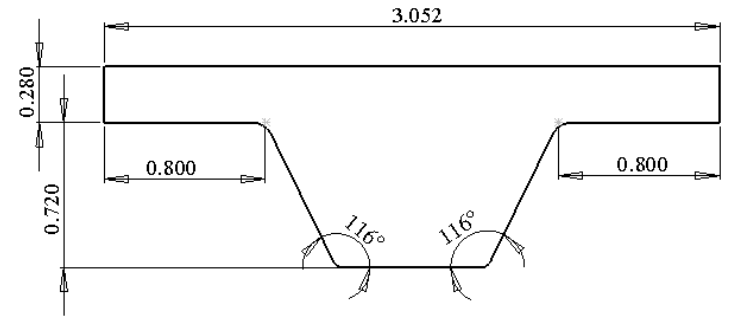

Figure 3. Illustration of upper die

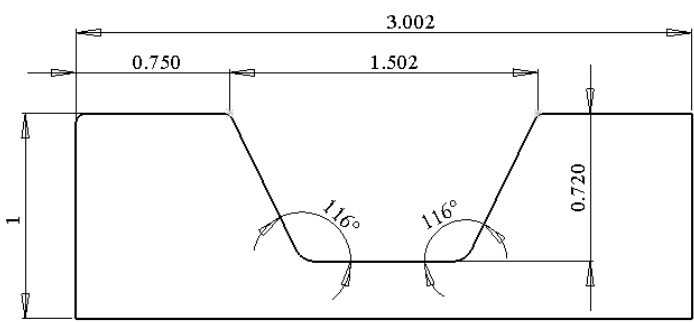

Figure 4. Illustration of lower die

Table 3 The material properties of the molds

\begin{tabular}{|c|c|c|}
\hline Desinty $\left(\mathrm{g} / \mathrm{cm}^{3}\right)$ & Elastic Modulus $(\mathrm{GPa})$ & Possion's ratio \\
\hline 7.8 & 206 & 0.3 \\
\hline
\end{tabular}

The finite element model is illustrated in Figure 5. The molds were modeled using solid elements, and the foil was modeled using shell elements. The foil feed from the left with a preset motion, and the rigid molds moved in vertical direction. The foil and rigid molds were constrained to prevent undesired motion. Two stamping steps were simulated to form two semi-hexagonal profiles. The calculation time was set to $0.3 \mathrm{~s}$. The simulated stamping process is shown in Figure 6.

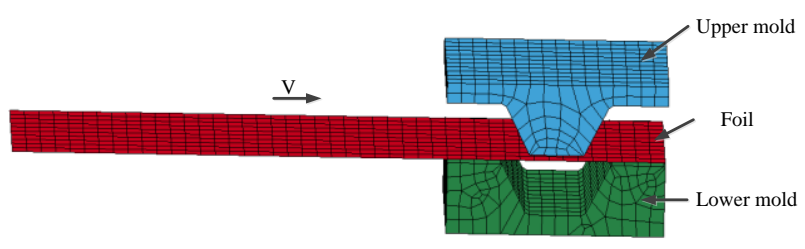

Figure 5. Finite element model of the molds and foil

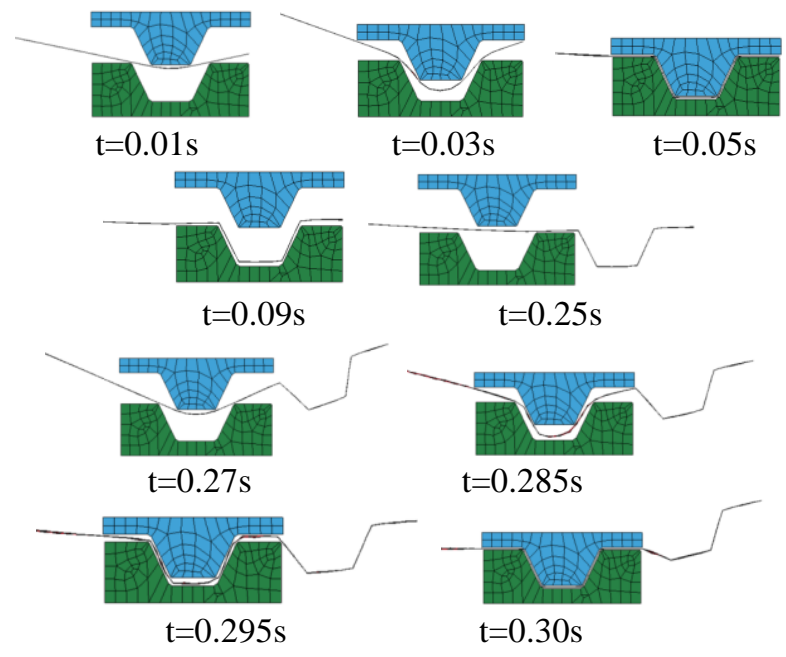

Figure 6 . The forming process of corrugated sheet metal

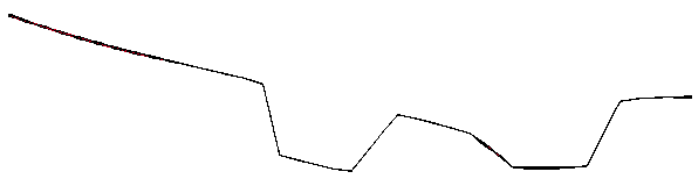

Figure 7. Formed corrugated sheet metal in the simulation

From Figure 6, we can see that there was a problem occurred at $0.295 \mathrm{~s}$. During the above forming process, the corrugated sheet formed by the first stamping step was not fixed. In the second 
stamping step to form the next semi-hexagonal profile, as the upper mold moved down, the first semi-hexagonal profile was taken into the range of the second stamping step. So the corner part of first semi-hexagonal profile was pressed and destroyed

\subsection{Optimization of Stamping Molds}

Two pressure dies used as fixture was designed as shown in Figure 8, to fix the formed semi-hexagonal profile during the first stamping step, and prevent the first semi-hexagonal profile destroyed by the second stamping step. Figure 9 shows the finite element model of the optimized molds and Figure 10 displays the new stamping process.

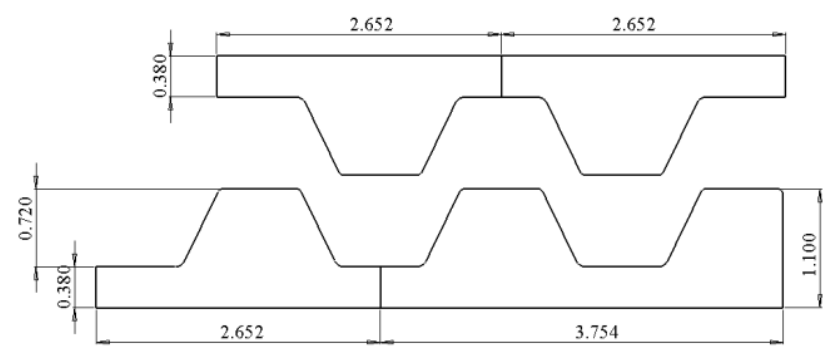

Figure 8 . The optimized molds with pressure dies

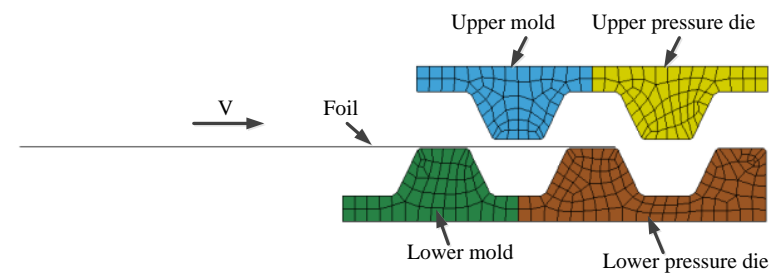

Figure 9. The finite element model of the optimized molds

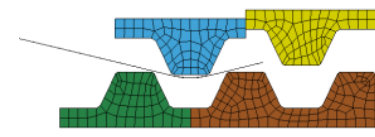

$\mathrm{t}=0.01 \mathrm{~s}$

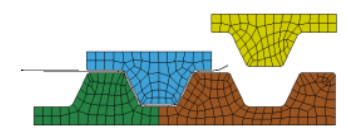

$\mathrm{t}=0.05 \mathrm{~s}$

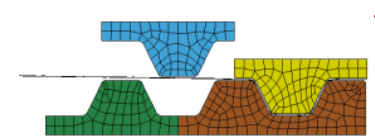

$\mathrm{t}=0.25 \mathrm{~s}$

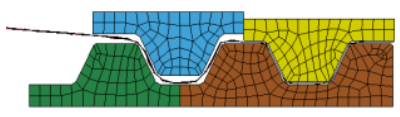

$\mathrm{t}=0.29 \mathrm{~s}$

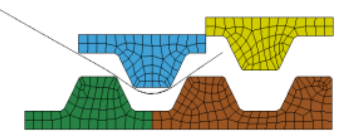

$\mathrm{t}=0.03 \mathrm{~s}$

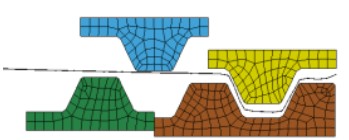

$\mathrm{t}=0.09 \mathrm{~s}$

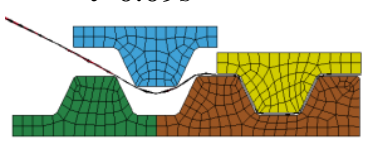

$\mathrm{t}=0.27 \mathrm{~s}$

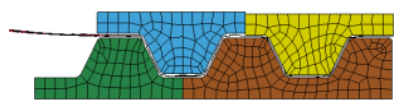

$\mathrm{t}=0.30 \mathrm{~s}$
Figure 10. The optimized stamping process

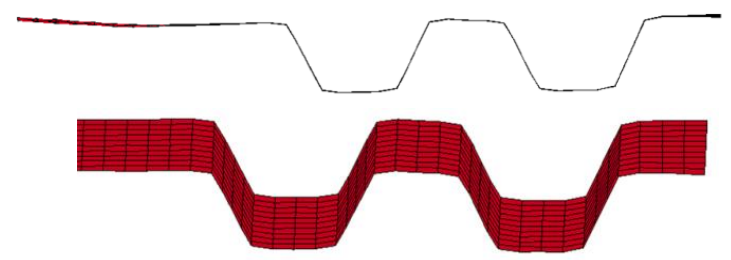

Figure 11. Corrugated sheet formed by optimized molds
Figure 11 shows the simulation results of the optimized molds. From the above forming process and results, we can see that the second stamping step didn't affect the formed shape after the first step any more.

\section{EXPERIMENTAL STUDY}

\subsection{Prototype Molds and Experimental Results}

On the basis of simulation, prototype molds were designed as shown in Figure 12. Stamping experimental results and the quality of the formed corrugated sheet is shown in Figure 13.

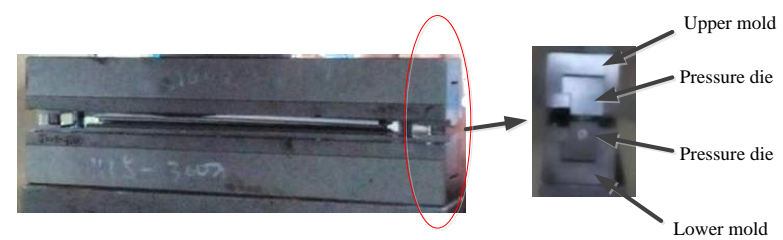

Figure 12. Prototype molds used in experiment

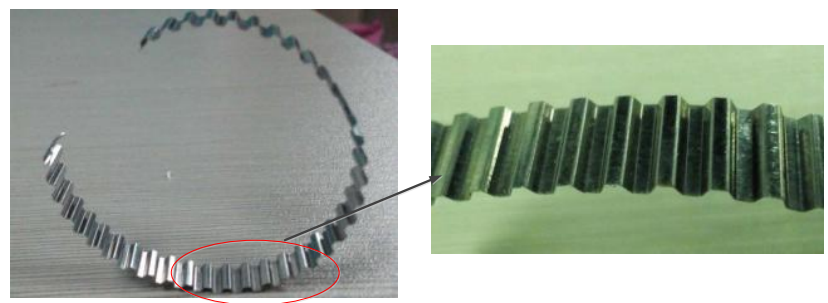

Figure 13. Formed corrugated sheet by prototype molds in experiment

\subsection{Forming Quality of Corrugated Sheet Metal}

An electron microscope was used to observe the corrugated sheet forming quality. As shown in Figure 14, the angle between adjacent sides is close to $120^{\circ}$, which means that the forming quality of every semi-hexagonal profile is very good.

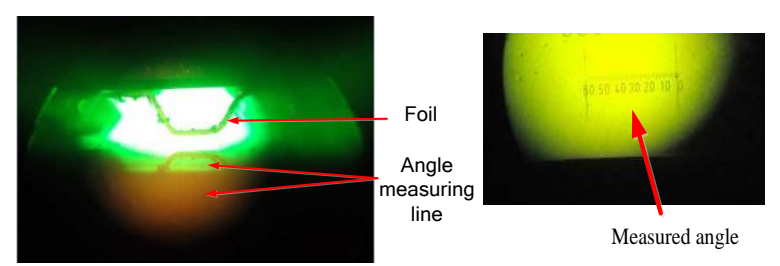

Figure 14. The following figure microscope corrugated sheet forming

But a serious problem also exists. As shown in Figure 13, overall curling phenomenon occurred. During the forming step of the second semihexagonal profile which began at $0.25 \mathrm{~s}$, the first semi-hexagonal profile was pressed firmly by the pressure dies. As the upper mold moved down, it was pulled by the adjacent part and the pulling force was transformed into residual stress. When all the 
molds removed, under the residual stress, the foil displays overall curing phenomenon

\subsection{Optimization of the Prototype Molds}

For serious curling phenomenon will affect the following welding process in honeycomb manufacturing, we increased the number of the pressure dies to three pairs. The molds now combine the function of both forming and granulating. The metal foil was moved to the granulating step after the forming step. The final optimized molds are shown in Figure 15. And the formed corrugated sheet metal is shown in Figure 16. The experimental result of the final optimized molds was much better than the prototype molds. But the curling still appeared because the residual stress still existed to some extent, which needed further research.

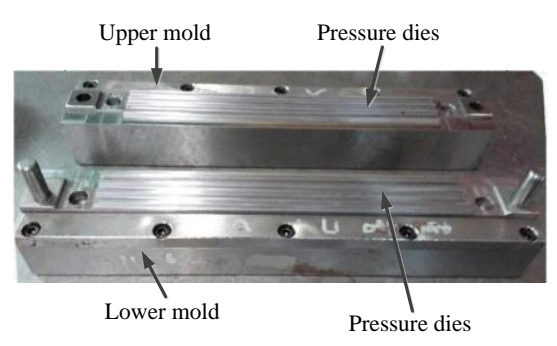

Figure 15. Final optimized molds

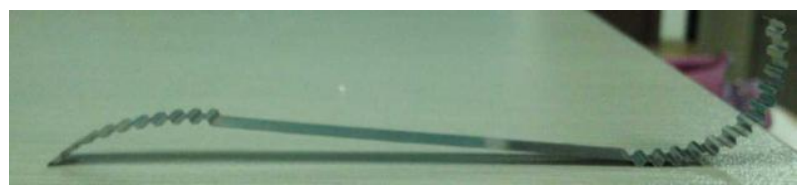

Figure 16. The formed corrugated sheet metal by the final molds

\section{CONCLUSIONS}

In this paper, finite element models for the corrugated sheet metal stamping process were built to analyze the forces and material deformation. The prototype molds were designed and tested, the experimental results and simulation results were consistent. Then according to the curling phenomenon occurred in the formed foil, the prototype molds were optimized. The final molds had three pairs of pressure dies. The formed corrugated metal sheet by the final molds was much better.

\section{ACKNOWLEDGEMENT}

This work was supported by "Guangdong Introduced Leading Talents" project, National Natural Science Foundation of China (No. 51105358), and Shenzhen Fundamental Research Project (No. JC201105190954A). The authors would like to thank the supports very much.

\section{REFERENCES}

[1] Doengi,F. \& Burnage,S.T. et al. 1998. Lander Shock Alleviation Techniques. ESA Bulletin. (93): 51-60.

[2] He,L.D. \& Ye, X.Q. et al. 2005. Investigation and Application of Honeycomb Seals. Chinese Mechanical Engineering, 1855-1857.

[3] Zhou,Z.F. 1995. Composite materials science. Packaging Engineering, 40-45

[4] Song,X.L. \& An,J.R. 2012. Metal material Handbook, Chemical Industry Press, 657-724. 